\section{Cultural Aspects of Palliative Cancer Care in Iran}

\author{
Sahar Fallahi, MSc; Maryam Rassouli, PhD, RN; Leila Khanali Mojen, PhD Candidate*
}

School of Nursing and Midwifery, Shahid Beheshti University of Medical Sciences, Tehran, Iran

\section{${ }^{*}$ Corresponding author}

Leila Khanali Mojen, PhD Candidate

School of Nursing and Midwifery

Shahid Beheshti University of Medical

Sciences, Tehran, Iran

Tel. +9821 88655372

Fax: +98 2188202521

E-mail: leilakhanali@yahoo.com

\section{Special Edition 1}

Article Ref. \#: 1000PMHCOJSE1110

\section{Article History}

Received: March 6 ${ }^{\text {th }}, 2017$

Accepted: June $5^{\text {th }}, 2017$

Published: June $6^{\text {th }}, 2017$

\section{Citation}

Fallahi S, Rassouli M, Mojen LK. Cultural aspects of palliative cancer care in Iran. Palliat Med Hosp Care Open J. 2017; SE(1): S44-S50. doi: 10.17140/ PMHCOJ-SE-1-110

\section{Copyright}

(C2017 Mojen LK. This is an open access article distributed under the Creative Commons Attribution 4.0 International License (CC BY 4.0), which permits unrestricted use, distribution, and reproduction in any medium, provided the original work is properly cited.

\section{ABSTRACT}

Palliative care is a human need, which is essential for patients with chronic disorders such as cancer, and aims to prevent and relieve pain and improve the quality of life (QoL) of patients and their families. Since culture is an important factor in predicting health behavior, it can be effective in providing these services. Thus, this review study has been conducted to assess the cultural aspects of palliative care in Iran. The findings were classified and provided based on the definition of palliative care on three major topics including early diagnosis, during treatment and disease period, and finally death and later. In the beginning of diagnosis, the most important element of palliative care is informing the disease to the patient and family. Disclosure of the disease in Iran is not culturally possible. The most important cultural barrier is cancer stigma in Iran, which affects the related measures such as screening diagnosis. The most important challenge in the treatment is pain management, which overshadowed factors such as cultural beliefs. Despite the challenges in the diagnosis and treatment of patients, which make the care difficult, the religious and spiritual context of Iranian people in the death and bereavement, as well as the strong family connections, are considered as a strong point that is helpful in the process of passing from the stage. According to the statement of the Union for International Cancer Control in 2008 based on "a better attitude toward cancer by 2020 and removing misconceptions about the disease", the available cultural opportunities in the country can be considered as areas in need of strengthening. The negative attitudes and beliefs can be reformed by adopting strategies such as increasing the awareness of the community as the first strategy in changing the culture.

KEY WORDS: Palliative care; Culture; Iran; Cancer.

\section{INTRODUCTION}

Cancer is the third cause of death in Iran after heart disease and accidents. ${ }^{1}$ According to global statistics of GLOBOCAN, more than 85,000 cases are reported and it is projected to have an ascending trend over the next decade due to increasing life expectancy and changing lifestyles. Considering the fact that this amount is estimated as much as $1,56,000$ people by $2030,{ }^{2}$ it will become one of the major health problems in Iran.

Since cancer patients experience many difficulties in all aspects of their lives, providing a comprehensive system in the form of a supportive and palliative care is required to avoid the influence of the negative consequences of the disease and improve the quality of life (QoL) of patients. ${ }^{1}$ Palliative care is the set of measures that aim to improve the QoL of patients and their families, in order to solve the problems caused by the disease. ${ }^{3}$ Palliative care is a holistic approach, which considers the physical, mental, social, and spiritual aspects of patients and their families and it is provided at the time of diagnosis and after death for their families. ${ }^{4}$ Presenting these services depends on various factors such as the economic, cultural and social status of every society. ${ }^{5}$ Therefore, providing palliative care regardless of cultural, anthropological, and even linguistic and semantic considerations not only do not reduce patients' pain, but also do not work anymore to relieve it. ${ }^{6}$ Cultural factors overshadow their behavior by affecting attitudes toward health and disease and it is considered as an important factor in 
treatment decisions especially in the end-of-life care. Iran is not excluded from this issue and the Iranian culture that will be dealt with in the following has a strong influence on such care. The fear of diagnosis leads to the lack of screening and the patient and the family would not be informed due to the concern of creating mental and spiritual distress in the patient. In such circumstances, it is clear that palliative care would not be possible easily. Even in the treatment stage, factors such as beliefs, cultural beliefs of different people with different religious and spiritual backgrounds and attitudes of individuals affect providing such services. Accordingly, this study was conducted to evaluate the cultural aspects affecting the palliative care at the time of diagnosis, during treatment, when dying, and after it in Iran.

\section{Iranian Culture}

Iran, with an area of $16,48,195$ square kilometers and a population of nearly 75 million people and the official language of Persian and religion of Islam is located in the southwest of the continent of Asia and it is one of the Middle East countries. ${ }^{3}$ Iranian culture covers centuries of knowledge, wisdom, traditions, and customs. Thus, it can affect people's life in many aspects of life. Iranian population, due to the passage of historical migrations has ethnic diversities, ${ }^{7}$ which has led to the formation of subcultures. The geographical location of Iran and the onslaught of different ethnic groups with different languages and religions during the past 3,000 years have led to the deployment of three Aryan language family, Sam (Arabic, Hebrew, Assyrian) and Urals, Altai (Turkish and Mongolian) as well as religions such as Zoroastrianism, Jewish, Christian and Islam in Iran $^{8}$ whose impact can be observed in the health behaviors so that different beliefs about the pain and mourning rituals of different ethnic prove this. ${ }^{9}$ On the other hand, given that the majority of Iranians are Muslims in particular, Shi'a and the national and official language is Farsi (Persian), these factors play an important role in cultural homogeneity between the different ethnic groups in Iran. ${ }^{8}$ In fact, the Iranian culture is the result of Iranian ethnic minorities' culture. ${ }^{7}$

\section{Analysis Method}

This study aimed to find information related to the cultural dimension of palliative care in Iran, by searching SCOPUS, Proquest, Ovid, PubMed, ScienceDirect, Google scholar, and
SID databases, with palliative care, cancer, chronic disease, and Iranian culture keywords. In addition, a wide range of data from journals, books, and publications were used on the sites. Finally, 53 relevant papers were selected (Figure 1). Inclusion criteria were, 1) papers were published between 2000 and 2016, 2) papers should have a variety of study methods, 3 ) papers should have full text, and 4) Papers are in Farsi and English.

\section{RESULTS}

260 papers were obtained. 53 papers were selected based on the research purposes and inclusion criteria and the results express and the findings indicated that palliative care is provided in the three stages of diagnosis, treatment, death, and after death that culture is known as an important factor in its presentation. These three stages have been studied separatedly in the following.

\section{First Stage}

Diagnosis: Palliative care begins with diagnosis, which challenges the cultural factors to provide in two stages of screening and telling the truth to the patient due to the stigma of cancer in this country.

Cancer screening: Screening is a method for early detection of cancer in people with the aim of reducing the spread of disease and deaths from it. ${ }^{10}$ in the developing countries, fear of cancer, lack of resources and lack of effective knowledge in avoiding screening for cancer are involved. ${ }^{11}$ The obstacles in Iran are factors such as fear of pain during mammography and its complications, high costs, lack of physician recommendation on mammography, ${ }^{12}$ the diagnosis of a serious illness and fear of rejection by their husbands, family members, and friends. In addition, Iran's religious background was involved in this attitude so that belief in fate and the will of God lead to their reluctance to do preventive measures. The torment of women and shame due to religious reasons prevent them from visiting a doctor. Sometimes even self-examination is considered embarrassing and uncomfortable for them. ${ }^{6,9}$ It can be said that these behaviors are rooted in individuals' attitudes and they are affected by Iraninan culture so that the result of the study on Iranian immigrant women in America was known as the most important factor of screening refusal. ${ }^{13}$

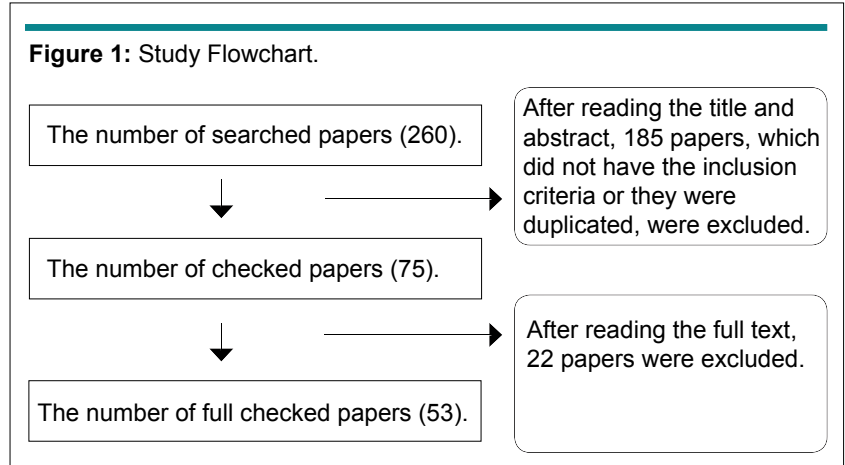


Telling the truth: Telling the truth in the medical profession is to provide the necessary information to enable the patient to make informed decisions about medical care and other aspects of life and informing him hher of the situation in which he $\backslash$ she is. ${ }^{14} 5$ to $66 \%$ of doctors believe that revealing the diagnosis of cancer and its prognosis is essential for the patient, ${ }^{15}$ while $37 \%$ of cancer patients in Iran are unaware of their disease diagnosis and $93 \%$ are unaware of their disease prognosis. ${ }^{16}$ In Western societies, "individual possession principle" has confirmed telling the truth to the patient, but in Eastern societies "lack of harm principle" has a higher priority than the individual possession. Given the centrality of the family in these communities, truth is concealed. ${ }^{17}$ In some cultures such as the culture of the communities in the Middle East and especially Iran, hiding the diagnosis and prognosis of cancer patients is not uncommon. Even, the disclosure of cancer may be considered as a rude, disrespectful, and damaging action. Some cultures believe that speaking about the incurable disease, death, and end-life-care would become a reality. ${ }^{18}$ In Iran, people equate cancer with death, and they still have not broken the taboo. ${ }^{19}$ This has caused that most of the people even doctors rarely use the word of "cancer" in their speaking and they mostly use "illness" as an alternative. ${ }^{16}$ For this reason, the truth of disease is concealed in Iran and doctors say the disease diagnose to a family member. ${ }^{19}$ Although, studies have shown that, in most cases, this is done at the request of the family ${ }^{20}$ because they believe that revealing the truth to the patient would lose hope and create additional distress. ${ }^{19}$ Some studies also showed that patients who do not know their disease have better life quality. ${ }^{21}$ Therefore, it can be said that the disease is highly considered as a family event rather than an individual event. ${ }^{22}$ For this reason, patients in Iran are primarily unaware of their diagnosis or they are the last one who becomes aware indirectly like seeing the folder, discussion with other patients, starting treatment such as chemotherapy, etc. ${ }^{3}$ However, the important point is whether the patients have a desire to know the truth or not? Several studies have shown that about 79 to $98 \%$ of patients want to know the diagnosis of their disease. ${ }^{23}$

The lack of formal training for doctors and nurses to deliver bad news to tell the information to patients with incurable diseases such as cancer can lead to psychological complications, especially anxiety and depression. Due to the taboo of cancer in Iran, if the news is informed in an inappropriate manner, the patients and their families will never forgive the treatment team and this is done properly, they will forget the treatment team. ${ }^{24}$

Cancer stigma: Stigma is the understanding and attitude of individuals from an unreasonably social judgment about a disease, which is highly influenced by the culture of that society. Factors such as imminent death, fear of symptoms and treatment, false beliefs regarding God's punishment have made cancer a stigma, ${ }^{25}$ which is interpreted differently by the required conditions of society and public opinion. It is also effective on the interaction of people with cancer patients, the patients' attitude to their illness, and their response so that fear of stigma can be a barrier to disclose a cancer diagnosis. ${ }^{26}$ In Iran, most people avoid to disclose their diagnosis due to avoid attracting others' sympathy, their curiosity, and the fear of losing connections. Even in cases, women hide their disease due to the fear of family members' concerns, changing their role of parents and spouses, the stigma of cancer and its legacy for the future of their children, and fear of losing job and they cause delay in starting treatment. Although, other beliefs including self-treatment, traditional medicine, and attention to others' recommendation cause delay in treatment, but the main reason is the cultural fields and stigma of cancer in the country. ${ }^{27}$ In the field of cancer prevention, fear of stigma is a major obstacle in self-examination, screening, and delays in identification of cancer symptoms. ${ }^{26}$

\section{The Second Stage}

Treatment: Palliative care in this stage is mostly focused on managing symptoms such as pain and supporting families because pain is a common symptom at this stage and taking drugs is an important factor in developing these services. Thus, this stage has discussed the cultural factors affecting pain management.

Pain and its management: Pain is an individual, subjective, and unique cultural experience and many factors have an impact on its experience that culture is one of them. ${ }^{9}$ Pain control is so important in the care of patients that the American Pain Society (APS) has introduced it as the $5^{\text {th }}$ vital sign. ${ }^{28}$ Pain in patients with cancer appears following primary tumor, metastasis tumor, radiation therapy, chemotherapy or surgery ${ }^{29}$ and not only is influenced by biochemical factors, but also is influenced by psychological and social factors. ${ }^{30}$ Pain created the most discomfort in cancer patients and it is seen in approximately 50$70 \%$ of these patients. ${ }^{29}$ Uncontrolled pains in cancer are one of the causes that push patients toward suicide. ${ }^{31}$ Therefore, pain and its control are one of the major challenges that culture has a significant role in it. ${ }^{32}$ Pain management is a response individuals' reaction to pain, which depends on individual beliefs and occurs in the form of behaviors such as drug seeking or no pain relief. On the other hand, understanding patients' beliefs requires good communication, which one of the care challenges in $\operatorname{Iran}^{33}$ and educational, managerial, organizational, and cultural factors are implicated in it. ${ }^{34}$ On the other hand, different languages and dialects in Iran and the country's religious principles because of the low relationship between men and women have doubled the problem. ${ }^{35}$

Religious and spiritual beliefs are decisive as an integral part of the culture in understanding and managing pain ${ }^{36}$ and they are known as a positive strategy for coping with pain. In Iranian mysticism, which is the origin of teachings of Islam, there are certain interpretations of pain and despite the emphasis on alleviating the pain and analgesia healthcare services, in some cases, not only people do not look for drug and treatment, but also seek voluntary pain because they consider the pain as a treatment and value. ${ }^{37}$ From the religious view, pain and 
suffering are atonement for the sins and the clearing agent for themselves and the community. ${ }^{38}$ Even, there are beliefs that pain is from God. As a task, the human is committed to stand the pain. Pain is an anticipated form of life. Pain and disease arose from divine decree and wisdom and there should not be mourn and impatience in this process because its bearing will follow God's mercy and grace.$^{37}$ However, sometimes the lack of expression of pain is due to the family structure. Since parents are the pillar of the family, they do not express their pain to preserve the family and the lack of pressure on the family. This case is even seen in the different Iranian ethnicities certain races have greater pain tolerance and it is related to their culture. ${ }^{39}$

Attitude is an important factor in behavior, which is rooted in the culture. Since taking drugs is essential in the management of cancer pain, negative attitudes towards opioids for fear of addiction is another pain management and palliative care challenges in Iran, which is a cultural challenge. ${ }^{40}$ Statistics provided by The International Narcotics Control Board (INCB) regarding the consuming opioid analgesic showed that Iranranked 115 in the world, 25 in Asia and 15 in the region is one of the countries with low consumption, which proves the claim. ${ }^{41}$ Although, one of the major reasons for this is the lack of knowledge and awareness of healthcare providers. ${ }^{4,41}$

\section{The Third Stage}

Death and bereavement: Palliative care ends by dying patients and 6 months after it, in which cultural factors is very effective on the two phenomena of death and mourning.

Death and dying: Death is the full and no return stop of critical actions. Patisson who provided a range of life and death theory believed that all humans have a trajectory based on the experiences and practices for their lives, but when a crisis arises, such as crisis awareness of death, the trajectory is changed and it passes three acute, chronic, and end stages. ${ }^{42}$ Iran is a country where about $98 \%$ of the population are Muslims, and death is one of the explained concepts in Islam. ${ }^{43}$ Death is culturally well expressed in Iran and people believe that death is not only is not the cut off the chain of complex biochemical processes, but also the soul continues to exist in death and death is only a passage from this world to the other world. ${ }^{44}$ This view of death and religiosity of the Iranian people leads to religious practices and worship when developing dangerous and serious diseases in the final days of life. From the cultural view, one of the cases in Iran that lead to peace or even slow death for patients with cancer is putting Quran overhead and bedside patient. ${ }^{38}$ There are different rules in the Islamic Iran to provide a quiet death for dying according to a religious context. According to Iran's dominant Islamic jurisprudence, to provide a quiet death for the dying, those around the dying person are obliged to lie down the dying so that his her feet are oriented toward Mecca. Sitting in front of the prayer, indoctrination if Declaration of Faith, reading verses from the Quran, not to leave along the dying, not to put heavy objects on the dying's chest and body, and not to talk too much are the most important needs of dying person to overcome initial difficulties of death. ${ }^{45}$ Therefore, to cope with the stresses of cancer and possible death, most of people turn to religious approaches to promote the mental health in patients. ${ }^{46}$ Despite the negative attitudes of nurses towards death and dying in Iran, which is highly due to the lack of training for nurses and their academic curriculum in Iran, ${ }^{4}$ there are still many spiritual strategies used in oncology that has rooted in religious and traditional beliefs. For example, their belief in God, divine wisdom in the events, God's power in helping humans and power of the supernatural source, relying on the power of trust in God, and resorting to Imams and death as help them to show more adaptive responses. ${ }^{44}$

Since in the dominant culture of Iranian society, it is preferred to perform the palliative care of the patient by families, especially in the final stages of life, ${ }^{47}$ the death place is another challenge that is rooted in culture. Many families in Iran still want to receive services in their own homes. However, there is no evidence on the conducted studies that show the tendencies and preferences of patients with cancer in Iran. ${ }^{48}$

Mourn: Mourn is one of the most common human reactions in all cultures and age groups in response to various types of loss, especially the death, ${ }^{49}$ that one of the aspect of palliative care is care at the stage of grief and the most common reactions that occur including denial, believing disaster, a sense of abandonment and anxiety, the desire to meet and search for a lost one, grief and constant reminding of the deceased, anger, guilt, transaction and switching mourn conditions to get rid of deep inner sadness and chagrin..$^{50}$ One of the most important factors that can affect the bereavement process can be social factors, including the level of education, support systems, gender forms, especially in terms of and cultural, religious and ethnic fields. ${ }^{51}$ In Iranian culture, numerous ceremonies, funerals, religious and spiritual contexts and familial support in this period have a significant impact in preventing loneliness, coping with the loss of loved ones ${ }^{52}$ and this is one of the strength points.

\section{CONCLUSION}

Culture is one of the important elements in providing palliative care and has a huge impact on the development of these services in any society and its necessity in the International Union statement of cancer in 2008 based on "improving attitudes towards cancer in 2020 and removing misconceptions about the disease". Therefore, in the following also demonstrated identifying the cultural context of each society is necessary and this study aimed to determine the cultural aspects of palliative care in Iran.

The results showed that, religious background is a strong point for the development of palliative care despite the challenges in Iran and the results of studies confirm in Islamic countries. ${ }^{53}$ In addition, misconceptions and negative attitudes towards the disease is rooted in the lack of knowledge as a major challenge 
in the country that can be improved by strategies so that Daher et al. introduced education as an important component in changing the culture. ${ }^{25}$ Therefore, the available cultural opportunities in the country can be considered as areas in need of strengthening. The negative attitudes and beliefs can be reformed by adopting strategies such as increasing community awareness as the first economic strategy in changing the culture in the form of public education and the importance of early screening in cooperation with charities, using media, training in schools as well as holding cancer campaign by the Ministry of Health, Medical Treatment and Education on the World Cancer Day.

\section{CONFLICTS OF INTEREST}

The authors declare that they have no conflicts of interest.

\section{REFERENCES}

1. Siegel R, DeSantis C, Jemal A. Colorectal cancer statistics, 2014. CA Cancer J Clin. 2014; 64(2): 17-104. doi: 10.3322/ caac. 21220

2. World health Organization. International Agency for Research in Cancer. Globocan 2012: Estimated cancer incidence, mortality and prevalence worldwide 2012. Web site. http://globocan.iarc. fr/Default.aspx. Accessed March 5, 2017.

3. Rassouli M, Sajjadi M. Cancer care in countries in transition: The islamic republic of Iran. In: Silbermann M, ed. Cancer Care in Countries and Societies in Transition. Berlin, Germany: Springer; 2016: 36-117.

4. Sajjadi M, Rassouli M, Mojen LK. Nursing education in palliative care in Iran. J Palliat Care Med. 2015. S4: 1.

5. Khosla D, Patel FD, Sharma SC. Palliative care in India: current progress and future needs. Indian J Palliat Care. 2012; 18(3): 149-154. doi: 10.4103/0973-1075.105683

6. Abrahm JL. Integrating palliative care into comprehensive cancer care. J Natl Compr Canc Netw. 2012; 10(10): 1192-1198. doi: 10.6004/jncen.2012.0126

7. Noorbakhsh Y. Culture and ethnicity; A model for cultural communication in Iran [In Persian]. Journal of Cultural Research. 2009; 1(4): 67-78.

8. Ahmadi Pour Z, Heidari Mouselo T, Heidari Mouselo T. Analysis of ethnicity and ethnic identity in Iran for sustainable security [In Persian]. Journal Management System. 2010; 2(1): $35-62$.

9. Nikbakht Nasrabadi A, Sanago K, Joybari L. A phenomenological analysis of post operative pain experiences in three subcultures in Iran [In Persian]. Hayat. 2005; 11(2 and 1): 33-40.

10. Mazloomy Mahmudabad S, Khodayarian M. The knowledge and attitude of women towards breast cancer screening behavior in Yazd city in 1391 [In Persian]. Iranian Journal of Breast Disease. 2014; 6(4): 41-51.

11. Aniebue UU, Onyeka TC. Ethical, socioeconomic, and cultural considerations in gynecologic cancer care in developing countries. International Journal of Palliative Care. 2014; 2014: 141627.

12. Rezaee Ghazdehi M, Amini L, Parvizi S, Hoseyni AF. Attitudinal barriers to mammography screening among women in Tehran [In Persian]. Journal Mazandaran University of Medical Sciences. 2013; 23(99): 69-75.

13. Kobeissi L, Samari G, Telesca D, Esfandiari M, Galal O. The impact of breast cancer knowledge and attitudes on screening and early detection among an immigrant Iranian population in southern California. J Relig Health. 2014; 53(6): 1759-1769.

14. Sadat Hosseini AS, Aramesh K. Ethical challenges of child care in the last stages of life [In Persian]. J Med Ethics. 2013; 7(25): 55-81.

15. Del Pozo PR, Fins JJ, Helmy I, et al. Truth-telling and cancer diagnoses: Physician attitudes and practices in Qatar. Oncologist. 2012;17(11): 1469-1474. doi: 10.1634/theoncologist.2012-0128

16. Zamanzadeh V, Rahmani A, Valizadeh L, et al. The taboo of cancer: the experiences of cancer disclosure by Iranian patients, their family members and physicians. Psychooncology. 2013; 22(2): 396-402. doi: 10.1002/pon.2103

17. Zamani A, Shahsanai A, Kivan S, Hematti S, Mokarian F. Iranian physicians and patients attitude toward truth telling of cancer [In Persian]. Journal of Isfahan Medical School. 2011; 29(143).

18. Searight HR, Gafford J. Cultural diversity at the end of life: Issues and guidelines for family physicians. Am Fam Physician. 2005; 71(3): 515-522. Web site. http://www.aafp.org/ afp/2005/0201/p515.html. Accessed March 5, 2017.

19. Zahedi F. The challenge of truth telling across cultures: A case study. J Med Ethics Hist Med. 2011; 4: 11.

20. Vahdaninia M, Montazeri A. Cancer patient education in Iran: attitudes of health professionals. 2003.

21. Montazeri A, Tavoli A, Mohagheghi AM, Roshan R, Tavoli Z. Disclosure of cancer diagnosis and quality of life in cancer patients: Should it be the same everywhere? BMC cancer. 2009; 9(1): 1. doi: 10.1186/1471-2407-9-39

22. Moazam F. Families, patients, and physicians in medical decisionmaking: A Pakistani perspective. Hastings Cent Rep. 2000; 30(6): 28-37. doi: 10.2307/3528451 
23. Motlagh A, Mafi AR, Hemati S, et al. Attitude of cancer patients toward diagnosis disclosure and their preference for clinical decision-making: A national survey. Arch Iran Med. 2014; 17(4): 232. doi: 014174/AIM.004

24. Parsa M, Bagheri A, Larijani B. Telling bad news to patients and its different aspects [In Persian]. $J$ Med Ethics Hist Med. 2011; 4(6): 1-14.

25. Daher M. Cultural beliefs and values in cancer patients. Ann Oncol. 2012; 23(suppl 3): 66-69. doi: 10.1093/annonc/mds091

26. Marlow LA, Wardle J. Development of a scale to assess cancer stigma in the non-patient population. BMC Cancer. 2014; 14(1): 1. doi: 10.1186/1471-2407-14-285

27. Mehrabi E, Hajian S, Simbar M, Hoshyari M, Zayeri F. The lived experience of Iranian women confronting breast cancer diagnosis. J Caring Sci. 2016; 5(1): 43-55. doi: 10.15171/ jes.2016.005

28. Pourghaznein T, Sabeghi H, Reihani T. Nurses opinions toward the Consumption of Morphine for pat ient s pain relief [In Persian]. Modern Care, Scientific Quarterly of Birjand Nursing and Midwifery Faculty. 2011; 8(1): 38-44.

29. Modesto-Lowe V, Girard L, Chaplin M. Cancer pain in the opioid-addicted patient: Can we treat it right? J Opioid Manag. 2011; 8(3): 167-175. doi: 10.5055/jom.2012.0113

30. Mori M, Elsayem A, Reddy SK, Bruera E, Fadul NA. Unrelieved pain and suffering in patients with advanced cancer. Am J Hosp Palliat Care. 2012; 29(3): 236-240. doi: 10.1177/1049909111415511

31. Asghari M, Karimzadeh N, Emarlow P. The role of painrelated beliefs in adjustment to cancer pain. 2005.

32. Juarez G, Ferrell B, Borneman T. Influence of culture on cancer pain management in Hispanic patients. Cancer Pract. 1998; 6(5): 262-269. doi: 10.1046/j.1523-5394.1998.00020.x

33. Asemani O. A review of the models of physician-patient relationship and its challenges [In Persian]. J Med Ethics Hist Med. 2012; 5(4): 36-50.

34. Mobasher M, Nakhaee N, Tahmasebi M, Zahedi F, Larijani B. Ethical issues in the end of life care for cancer patients in Iran. Iranian journal of public health. 2013; 42(2): 188.

35. Norouzinia R, Aghabarari M, Shiri M, Karimi M, Samami E. Communication barriers perceived by nurses and patients. Glob J Health Sci. 2015; 8(6): 65.

36. Coolen PR. Cultural relevance in end-of-life care. Ethno Med. 2012. Web site. https://ethnomed.org/clinical/end-of-life/ cultural-relevance-in-end-of-life-care. Accessed March 5, 2013.

37. Dadkhoda KH. Mystical concept of "pain" in Masnavi Manavi [In Persian]. 2014.

38. Abedi M. Palliative care within the Iranian context: Redefining palliative care, deploying spirituality as a support measure and need for cultural sensitivity. Spirituality. 2012: 249258. Web site. http://www.inter-disciplinary.net/wp-content/ uploads/2012/02/abedisppaper.pdf. Accessed March 5, 2017.

39. Heydarpour S, Zare E, Mehrabi E, Heidarpour F, Kolivand M. Comparison of primipara's women perception of pain, fear and anxiety of vaginal delivery among Persian, Kurdish and Turkish women. Journal of Clinical Research in Paramedical Sciences. 2015; 4(3): 223-230.

40. Ghezeljeh TN, Hosseini AF. Attitudinal barriers to effective cancer pain management. Hayat. 2012; 18(1): 89-101.

41. Rassouli M, Sajjadi M. Palliative care in Iran moving toward the development of palliative care for cancer. American Journal of Hospice and Palliative Medicine. 2014.

42. Imani Far HR, Bostani GH, Dodman F, Raisi RA. Confronting death from Quranic and psychological viewpoints [In Persian]. Interdiscipilinary Quranic Studies. 2011; 2(4): 65-72.

43. Zahedi F, Larijani B, Bazzaz JT. End of life ethical issues and Islamic views. Iran J Allergy Asthma Immunol. 2007; 6(Suppl 5): 5-15. Web site. http://emri.tums.ac.ir/upfiles/91787548.pdf. Accessed March 5, 2017.

44. Zamanzadeh V, Rassouli M, Abbaszadeh A, et al. Spirituality in Cancer Care: A Qualitative Study. Journal of Qualitative Research in Health Sciences. 2014; 2(4): 366-378.

45. Kazemi AH, Kazemi M, Abbasi M, et al. Assessing end of life support. Medical Ethics and History of Medicine. 2012; 5(2): 45-57.

46. Heidarzadeh M, Rassouli M, Shahbolaghi FM, et al. Posttraumatic growth and its dimensions in patients with cancer. Middle East Journal of Cancer. 2014; 5(1): 23-29.

47. Razzak R, Smith TJ, Palliative Care to the Cancer Patient: The Middle East as a Model for Emerging Countries. Hauppauge, NY, USA: Nova Science Publishers, Inc; 2014.

48. Rassaf MR, Ramezani R, Mehrazma M, Rassaf MRR, Asadi-Lari M. Inequalities in Cancer Distribution in Tehran; A Disaggregated Estimation of 2007 Incidence by 22 Districts. Int J Prev Med. 2012; 3(7): 483-492.

49. Sharifi M, Fatehizade M, Ahmadi A. Psychometric properties of the Hogan Grief reaction checklist in Iranian bereaved families 
[In Persian]. Knowledge \& Research in Applied Psychology. 2013; 14(3): 69-79.

50. Maymandi V, Jamshidi F. The representation of Psychologic mourning stages in the poems of mothers in the Jahilid era. Arabic Literature. 2012; 4(3): 247-272.

51. Muller ED, Thompson CL. The experience of grief after bereavement: A phenomenological study with implications for mental health counseling. Journal of Mental Health Counseling.
2003; 25(3): 183. doi: 10.17744/mehc.25.3.wu4n7dljyekuh4ef

52. Student MSPD, Fatehizade M, Ahmadi SA. Psychometric Properties of the hogan grief reaction checklist in Iranian bereaved families.

53. Seyedfatemi N, Borimnejad L, Mardani Hamooleh M, Tahmasebi M. Interpretation of palliative care concept, its barriers and facilitators using meta-synthesis. Mod Care J. 2014; 11(4): 316-329. 